\title{
Prostate Biopsy Strategies: Current State of the Art
}

\author{
Badar M. Mian, MD, Albany, New York
}

Key Words

$\overline{\text { Prostate, biopsy, scheme, cancer, detection, atypia, high-grade PIN }}$

\begin{abstract}
Prostate-specific antigen testing and prostate biopsy have revolutionized our ability to detect prostate cancer at an early stage. The transrectal ultrasound-guided biopsy procedure has undergone a number of modifications over the past 10 years to meet our goal of early detection of cancer at a curable stage. Biopsy schemes have evolved from lesion-directed biopsies to systematic mapping of the peripheral zone of the prostate, which harbors almost all of the significant tumor foci. An increase in the number of biopsy cores from 6 to 10 (or 12) has resulted in a significant improvement in the detection of clinically localized cancer, without any appreciable increase in the number of indolent cancers. Current biopsy schemes also have enhanced our ability to determine the true prognostic value of pathologic lesions such as high-grade prostatic intraepithelial neoplasia and atypical small acinar proliferation which have been associated with cancer detection in repeat biopsies. I discuss the rationale behind, and the outcomes of, various biopsy strategies. More than 15 years after PSA testing was popularized for early detection, a number of men are presenting for evaluation regarding repeat prostate biopsy for various clinical indications. The indications, biopsy scheme, and cancer detection rates for repeat prostate biopsy are discussed in detail. (JNCCN 2004;2:213-222).
\end{abstract}

In 1987, the FDA approval of the prostate-specific antigen (PSA) test for early detection of prostate cancer, along with the availability of transrectal ultrasound (TRUS) probes and spring-loaded biopsy needles, heralded a new era in the early detection of prostate cancer.

From the Department of Surgery/Urology, Albany Medical College, Stratton VA Medical Center, Albany, New York.

Received January 4, 2004; accepted for publication February 19, 2004.

The author has no financial interests, arrangement, or affiliations with the manufacturers of any products discussed in the article or with their competitors.

Correspondence: Badar M. Mian, MD, Assistant Professor of Surgery/Urology, Albany Medical College, Stratton VA Medical Center, 23 Hackett Boulevard, Albany, New York 12208. E-mail: mianb@mail.amc.edu
At present, TRUS-guided prostate biopsy is one of the most common urologic procedures, with nearly 500,000 biopsies performed each year. In 2003, an estimated 220,000 new cases of prostate cancer were diagnosed in the United States. ${ }^{1}$ Although PSA remains the most common, and perhaps the most useful, serum marker for the early detection of prostate cancer, the biopsy technique itself has undergone extensive modifications.

\section{Sextant Biopsy Scheme: The Early Years}

Soon after the introduction of PSA, Hodge et al. ${ }^{2}$ introduced a systematic, sextant biopsy scheme that allowed an increase in the cancer detection rate at an early, potentially curable stage (Fig. 1). As described originally, the sextant biopsy cores were obtained from the mid-lobar, parasagittal plane at the base, mid, and apex of each lobe (6 cores). They found that this strategy of systematic biopsy detected significantly more cancers than those found by digital rectal examination (DRE) or by directing biopsy sampling toward sonographic lesions alone. ${ }^{2}$ Although the distribution of these sextant cores was not based on any specific anatomic findings, this scheme did allow for a symmetric and reproducible method of sampling the prostate.

This approach to prostate sampling remained popular for many years, until anatomic studies of prostatectomy specimens revealed that most of the significant tumors were found in the posterolateral (or peripheral zone) prostate. In 1995, Stamey ${ }^{3}$ suggested that the biopsy tracts should be moved laterally to maximize the yield from the sextant biopsies. The cancer detection rate for men with a PSA level between 4 and $10 \mathrm{ng} / \mathrm{mL}$ was close to $25 \%$ after a standard sextant biopsy. ${ }^{4}$

\section{Transition Zone Biopsies}

In addition to the standard sextant biopsies that sampled the peripheral zone, several authors ${ }^{5,6}$ found a significant number of prostate cancers detected only in transition 

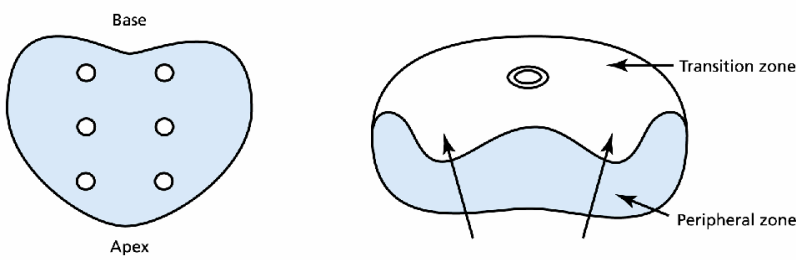

Figure 1 Sextant biopsy scheme. (A) Posterior view demonstrating the site of biopsy cores at the base, mid and apex of each lobe. (B) Transverse view showing a biopsy core obtained from the mid-lobar, parasagittal plane, half of the distance between midline and the lateral edge of the prostate.

zone (TZ) biopsies. Thus, performing TZ biopsies, in addition to the standard sextant biopsies, became standard practice in men undergoing the first prostate biopsy. However, in the mid-1990s, several studies ${ }^{7-11}$ reported an exceedingly low cancer detection rate for TZ biopsies (Table 1). The utility of TZ biopsy cores was questioned, and a uniform recommendation from most authors was that the TZ biopsies could be safely omitted in patients undergoing the first prostate biopsy. The decline in TZ-only cancer detection rate was probably caused by the "cull effect," that is, that most of the large transition zone tumors present in the population that was screened were detected in the first few years. Also possible is the explanation that our improved ability in sampling the peripheral zone resulted in a decrease in the TZ-only cancers, because most of the transition zone biopsies also were positive in the peripheral zone.

Critical analysis of the role of transition zone biopsies by Liu et al. ${ }^{12}$ and others showed that TZ biopsy in men with a previous negative sextant biopsy was associated with a cancer detection rate of $9 \%$ to $15 \%$. Presently, the transition zone biopsy is reserved for men undergoing a repeat biopsy, which will be further discussed later in the article.

\section{Sextant Biopsies and Sampling Error}

As a direct consequence of early detection and aggressive treatment of clinically localized prostate cancer, an ever-increasing number of prostate specimens became available to the researchers. After detailed histopathologic examination of these specimens, researchers recognized that the tumors found in biopsy specimens often did not correlate with the total tumor volume or the location of dominant tumor in the radical prostatectomy specimen. In addition, several investigators noted that a significant number of men who had previously undergone negative prostate biopsy were found to have cancer in the second biopsy (Table 2).

To determine the false-negative rate of sextant biopsy, a repeat sextant biopsy was performed soon after the initial negative biopsy for various indications. The false-negative rate ranged from $20 \%$ to $40 \%$ after a negative sextant biopsy. These authors ${ }^{13-15}$ recommended that a repeat sextant biopsy should be performed in all men with a negative biopsy. Levine et al. ${ }^{16}$ performed two sets of sextant biopsies during the same session and found that $30 \%$ of cancers were found only in the second set of biopsies, and recommended that all men undergo two sets of sextant biopsies during the first biopsy session.

The sextant biopsy scheme, and the associated falsenegative rate, was clearly inadequate in achieving the goal of early detection of significant prostate cancer. Researchers recognized that a greater number of tumors were detected by increasing the number of biopsy cores and sampling the lateral peripheral zone, and the sextant biopsy scheme was generally abandoned in favor of more extended prostate biopsy schemes.

\section{Extended Biopsy Schemes}

Initial attempts at improving prostate sampling consisted of increasing the number of biopsy cores from the

\section{Table 1 Cancer Detection Rate Specific to Transition Zone Biopsy}

\begin{tabular}{|lllll|} 
Author & Period & Scheme & Cancer in T-zone alone (\%) & Conclusion \\
\hline Reissigl et al. $^{6}$ & $1993-96$ & Sextant +2 T-zone & 28 & Should be routine \\
Chang et al. $^{5}$ & $1994-97$ & Sextant +2 T-zone & 13 & Consider for glands $>50 \mathrm{~mL}$ \\
Bazinet et al. $^{7}$ & 1994 & Sextant +2 T-zone & 2.9 & Not useful \\
Onder et al. $^{8}$ & $1995-96$ & Sextant +2 T-zone & 1.9 & Not useful \\
Fowler et al. $^{9}$ & $1995-97$ & Sextant +2 T-zone & 1 (1st biopsy) 2 (repeat biopsy) & Not useful \\
Maeda et al. ${ }^{10}$ & 1997 & Sextant +2 T-zone & 0 (1st biopsy) 50 (2/4 in repeat biopsy) & Not useful for 1 st biopsy \\
Liu et al. ${ }^{11}$ & $1995-2000$ & Sextant +2 T-zone & 1.5 (1st biopsy) 9.5 (repeat biopsy) & Not useful for 1 st biopsy \\
\hline
\end{tabular}


State-of-the-Art-Prostate Biopsy

\begin{tabular}{|c|c|c|c|c|}
\hline $\begin{array}{l}\text { Author } \\
\text { year }\end{array}$ & $\begin{array}{l}\text { Initial scheme, } \\
\text { repeat scheme }\end{array}$ & $\begin{array}{l}\text { Cancers detected } \\
\text { on repeat biopsy }\end{array}$ & Predictor of cancer & Conclusion \\
\hline $\begin{array}{l}\text { Keetch et al. }{ }^{13} \\
1994\end{array}$ & $\begin{array}{l}\text { Sextant, } \\
\text { Sextant }\end{array}$ & $21 \%$ & $\begin{array}{l}\text { PSA, PSA } \\
\text { velocity }\end{array}$ & Re-biopsy all men \\
\hline $\begin{array}{l}\text { Roehrborn } \\
\text { et al. } .^{14} 1996\end{array}$ & $\begin{array}{l}\text { Sextant, } \\
\text { Sextant }\end{array}$ & $\begin{array}{l}23 \% \\
37 \% \text { for } P S A>10\end{array}$ & N/A & Re-biopsy all men \\
\hline $\begin{array}{l}\text { Fleshner et al. }{ }^{15} \\
1997\end{array}$ & $\begin{array}{l}\text { Sextant, } \\
\text { Sextant }\end{array}$ & $\begin{array}{l}30 \% \\
24 \% \text { in low-risk }\end{array}$ & N/A & Re-biopsy all men \\
\hline $\begin{array}{l}\text { Levine et al. }{ }^{16} \\
1998\end{array}$ & $\begin{array}{l}2 \text { sextants in } \\
\text { one session }\end{array}$ & $30 \%$ & N/A & $\begin{array}{l}2 \text { sextants for } \\
\text { all men }\end{array}$ \\
\hline
\end{tabular}

peripheral zones by incorporating the lateral-anterior horn of peripheral zone (Fig. 2). The lateral peripheral zone biopsy cores are obtained from the area just medial to the lateral border of the prostate. This article details the differences among the various extended biopsy schemes, the rationale for selecting biopsy sites, and the cancer detection rates.

In 1997, Eskew et al. ${ }^{17}$ described a 5-zone extended biopsy scheme that incorporated biopsies from the lateral and midline, peripheral zone (Fig. 3). The total number of cores obtained was 13 , but the number of cores was increased to 18 for larger glands. Of the 119 patients, cancer was found in $48(40 \%)$ patients, and 17 of 48 cancers were present only in the additional biopsy cores. Interestingly, the 3 midline peripheral zone biopsies yielded the fewest numbers of cancers but were associated with the highest rate of complications including hematuria, which was noted in nearly three fourths of the patients.

Babaian et al. ${ }^{18}$ compared the cancer detection rates of an 11-core, extended, multisite biopsy scheme with that of the sextant biopsy scheme. Their extended biopsy scheme was based on work reported by Chen et al. ${ }^{19}$ that showed the location of tumor foci that were missed by the standard sextant scheme. They mapped and digitized 607 tumor foci from wholemount, radical prostatectomy specimens and performed

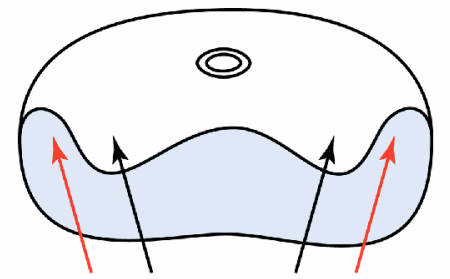

Figure 2 Transverse view of the prostate depicting the peripheral zone biopsy at sextant site (black arrows), and the lateral horn of peripheral zone (red arrows). computer-simulated biopsies on a digitally reconstructed prostate model. The tumors missed by the sextant biopsy scheme were found to be in the anterior horn of peripheral zone, midline peripheral zone, and transition zone. These zones were incorporated in the extended biopsy scheme (Fig. 4).

Of the 362 patients, 110 (36\%) had cancer and 36 (33\%) patients had cancers only in the extended biopsy sites. Further analysis of individual biopsy sites revealed that the cancer detection yield from the midline peripheral zone and the transition zone was minimal. Thus, the sites with minimal yield were eliminated, and a 10-core biopsy scheme was adapted that included one additional anterior horn peripheral zone core, similar to the one described in the proceeding section.

Presti et al. ${ }^{20}$ evaluated a 10 -core extended biopsy scheme that included 2 additional cores from the lateral peripheral zone from each side (Fig. 5). For glands more than $50 \mathrm{~mL}$ in size, anteriorly directed (transition zone) sextant biopsies were also added for 16 biopsy cores. Of the 483 patients evaluated, 202 (42\%) had cancer, and $40(20 \%)$ of the cancers were missed by the standard sextant biopsy scheme. In addition, the authors noted that the anteriorly directed biopsies and the midlobar base biopsy yielded a minimal number of cancers and could be omitted from the biopsy scheme for the initial biopsy patient.

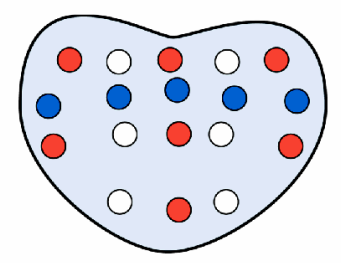

Figure 3 Five-region biopsy scheme. Thirteen peripheral zone cores are obtained form the sextants sites (white dots), lateral prostate and midline (red dots). For prostate glands larger than $50 \mathrm{cc}, 1$ additional core is obtained from each zone (dark blue dots), for a total of 18 cores. 


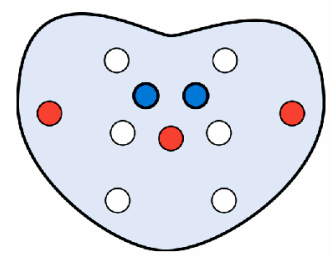

Figure 4 Eleven-core, multisite biopsy scheme. In addition to the sextant site cores (white dots), 1 additional core was taken from each of the transition zones (blue dots), midline, and lateral horn of peripheral zone (red dots).

Gore et al. ${ }^{21}$ evaluated a 12-core biopsy scheme that included the sextant biopsies and 3 additional lateral cores from base, mid, and apex from each side (Fig. 6). Prostate cancer was found in 160 (39\%) of the 396 men who underwent a biopsy. The biopsy cores from the sextant sites would have missed 39 (24\%) patients with cancer. In determining the specific yield form each biopsy core, the authors noted that none of the cancers were detected by the mid biopsy from the sextant scheme.

All of the extended biopsy techniques detected a number of cancers that would have been missed by the sextant biopsy technique. The improvements in the cancer detection rates ranged form $20 \%$ to $35 \%$ for various extended biopsy schemes when compared with that of the sextant scheme (Table 3 ). We should note that of all of the extended biopsy schemes presented here, none is significantly better than others in terms of cancer detection. The differences in the cancer detection rates may only be because of differences in patient characteristics. Legitimate concerns were raised whether increased prostate sampling also will detect a higher number of potentially insignificant prostate cancers. A few recent studies on extended biopsy scheme have showed that although the number of early stage, clinically localized cancers is increased, no increase exists in the detection rate of insignificant cancers. ${ }^{22,23}$

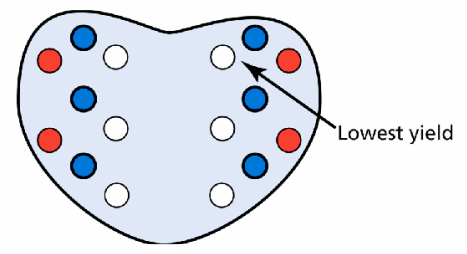

Figure 5 Ten-core biopsy scheme. In addition to sextant peripheral zone cores (white dots), 2 biopsies are obtained from each of the lateral, anterior horns (red dots). For larger glands, sextant anteriorly directed (or transition zone) biopsies (blue dots) also were obtained (16 cores). The midlobar, base biopsy yielded the fewest cancers.

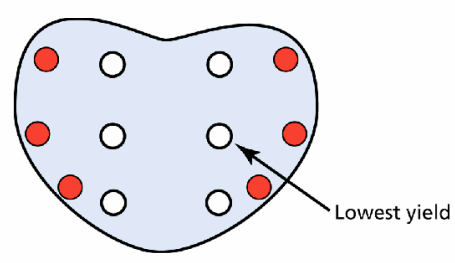

Figure 6 Twelve-core biopsy scheme. Peripheral zone is sampled at the sextant sites (white dots) and at the lateral horn of peripheral zone (red dots) bilaterally. The sextant core at mid prostate detected the least number of cancers.

Also apparent is that merely increasing the total number of biopsy cores does not yield a higher cancer detection rate..$^{24}$ The biopsies must be obtained from areas of the prostate known to harbor significant cancers, such as the peripheral zone including the anterior (lateral) horns. For men undergoing the first biopsy, I use a 10-core peripheral zone biopsy scheme for smaller glands and obtain an additional core at the lateral apex from each side for larger glands (Fig. 7).

\section{Repeat Prostate Biopsy}

More than 15 years after the PSA test and TRUS guided prostate biopsies were popularized, many men return for further evaluation of rising PSA, an interval change in the DRE, or for a persistently elevated PSA that is out of proportion to the prostate size. Many men undergo repeat prostate biopsies for the above-mentioned clinical indications as well as the presence of pathologic lesions that have been associated with a high risk of cancer in the subsequent biopsies, that is, high-grade prostatic intraepithelial neoplasia (HGPIN) and atypical small acinar proliferation (ASAP or atypia).

Although the initial biopsy is often based on a PSA threshold, the criteria for repeat biopsies are often based on scenarios that require clinical judgment, such as a determination by a urologist that a given PSA level is still too high or has risen significantly. Similarly, the diagnosis of HGPIN or ASAP may depend in large part upon the pathologist's thoroughness and his determination that the biopsy specimen contains enough abnormalities to render such a diagnosis. In addition, the prostate biopsy scheme that is used for the first biopsy may have an effect on the results of a second biopsy. Because the prostate is rebiopsied in men who are thought to have cancer in the prostate at that moment in time, the repeat biopsy can be performed immediately after the first biopsy. The interval between biopsies is related more to the 


\begin{tabular}{|c|c|c|c|c|c|}
\hline Author year & Biopsy Scheme & Total patients $N$ & With cancer $\boldsymbol{N}(\%)$ & $\begin{array}{l}\text { Extended site } \\
\text { only cancers, } N\end{array}$ & $\begin{array}{l}\text { Detection rate } \\
\text { improved (\%) }\end{array}$ \\
\hline $\begin{array}{l}\text { Eskew et al. } .^{77} \\
1997\end{array}$ & $\begin{array}{l}\text { 5-region } \\
13-18 \text { cores }\end{array}$ & 119 & $48(40)$ & 17 & 35 \\
\hline $\begin{array}{l}\text { Babaian et al. }{ }^{18} \\
2000\end{array}$ & 11-core & 362 & $110(30)$ & 36 & 33 \\
\hline $\begin{array}{l}\text { Presti et al. }{ }^{20} \\
2000\end{array}$ & 10-12 cores & 483 & $202(42)$ & 40 & 20 \\
\hline $\begin{array}{l}\text { Gore et al. }{ }^{21} \\
2001\end{array}$ & 12-core & 396 & $160(40)$ & 39 & 24 \\
\hline
\end{tabular}

scheduling issues and patient wishes rather than any medical or scientific evidence. In general, the studies mentioned in this section performed repeat biopsies between 6 weeks and 1 year after initial biopsy.

One must remember that, despite the tremendous improvements in the prostate cancer detection rates, the biopsy procedure is a systematic but random sampling of the prostate, because prostate cancer does not have a specific echo pattern on ultrasound. Inadequate sampling at first biopsy may be associated with a high cancer detection rate at second biopsy (as seen with sextant biopsies), or vice versa. Thus, the false-negative rate can only be minimized and may not be completely eliminated. This article separately discusses the strategies and outcome of repeat prostate biopsy in men with the following indications: 1) clinical (rising PSA or abnormal DRE); 2) HGPIN; and 3) ASAP.

\section{Rising PSA or Abnormal DRE}

The rate of cancer detection at repeat sextant biopsy after a negative sextant biopsy is shown in Table 2 . Most of these men had a second sextant biopsy because of the clinical indications listed above. In Table 4, we summarize the results of repeat extended biopsy scheme in men at high risk (rising PSA or abnormal DRE) of cancer after an initial negative sextant or extended

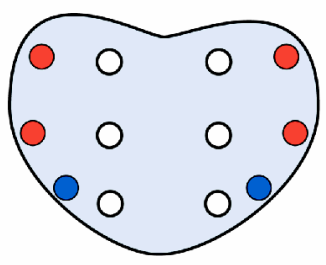

Figure 7 Our present scheme. Cores are taken form the sextant sites (white dots), and 2 from each lateral horn (red dots) at base and mid gland ( 10 cores). For glands larger than $30 \mathrm{cc}$, an additional core (black dot) is obtained from each apex (12 cores). biopsy. Babaian et al. ${ }^{18}$ reported on a subset of 277 men who underwent a repeat biopsy using the 11-core, multisite, extended biopsy scheme after a previous negative sextant biopsy result. Of the 277 men evaluated, prostate cancer was found in $81(29 \%)$ men. Of note, cancer was found only in the extended sites in 33\% of men. In contradistinction to these findings, when men underwent an initial biopsy using the extended scheme, the cancer detection rate on repeat biopsy was significantly reduced, ${ }^{25}$ that is, a lower false-negative rate was found. The mean Gleason score was 6 and the cancer was detected in only one core in nearly $75 \%$ of men.

Thus, it appears that use of the extended biopsy scheme for first biopsy session not only improves the cancer detection rate, but also minimizes the inherent false-negative rate associated with systematic sampling of the prostate.

\section{High-Grade PIN}

High-grade prostatic intraepithelial neoplasia (HGPIN) is characterized by the presence of atypical cells, which line the normal prostatic acini. The cytologic changes are similar to those seen in cancer, including atypical or large nuclei, prominent nuclei, hyperchromatism, and loss of polarity. Sufficient evidence nominates HGPIN as the precursor to prostate cancer. ${ }^{27,28}$ Recent data from animal models strongly support the theory that progression to a malignant phenotype involves passage through an intermediate stage of intraepithelial neoplasia or HGPIN..$^{29,30}$

A high degree of association can be found between prostate cancer and the presence of HGPIN within the same prostate. Several autopsy studies and studies of whole-mount prostate specimen after radical prostatectomy or radical cystectomy have identified coexisting HGPIN and cancer in up to $90 \%$ of men. ${ }^{31-33}$ Previous reports have noted the presence of 


\begin{tabular}{|c|c|c|c|c|c|c|}
\hline Author Year & $\begin{array}{l}\text { Initial biopsy } \\
\text { scheme }\end{array}$ & $\begin{array}{l}\text { Repeat biopsy } \\
\text { scheme }\end{array}$ & $\begin{array}{l}\text { Positive/Total } \\
\text { N/N (\%) }\end{array}$ & $\begin{array}{l}\text { Positive } \\
\text { sextant only, } N(\%)\end{array}$ & $\begin{array}{l}\text { Positive } \\
\text { extended only } N(\%)\end{array}$ & $\begin{array}{l}\text { Both sites } \\
\text { positive } N(\%)\end{array}$ \\
\hline $\begin{array}{l}\text { Babaian et al. }{ }^{18} \\
2000\end{array}$ & Sextant & $\begin{array}{l}\text { 11-core } \\
\text { Extended }\end{array}$ & $81 / 277(29)$ & $20(25)$ & $27(33)$ & $34(42)$ \\
\hline $\begin{array}{l}\text { Chan et al. } .^{22} \\
2002\end{array}$ & Sextant & $\begin{array}{l}\text { 10-core } \\
\text { Extended }\end{array}$ & $67 / 185(36)$ & $13(19)$ & $17(26)$ & $37(55)$ \\
\hline $\begin{array}{l}\text { Mian et al. } .^{25} \\
2002\end{array}$ & $\begin{array}{l}\text { 11-core } \\
\text { Extended }\end{array}$ & $\begin{array}{l}\text { 11-core } \\
\text { Extended }\end{array}$ & $5 / 47(10)$ & $1(20)$ & $2(40)$ & $2(40)$ \\
\hline $\begin{array}{l}\text { Moore et al. } .^{26} \\
2003\end{array}$ & $\begin{array}{l}\text { Extended } \\
(\geqslant 10 \text { cores })\end{array}$ & $\begin{array}{l}\text { Extended } \\
\text { ( } \leqslant 10 \text { cores) }\end{array}$ & $7 / 78$ (9) & $2(29)$ & $3(43)$ & $2(29)$ \\
\hline
\end{tabular}

HGPIN alone in $1 \%$ to $20 \%$ of the biopsy specimens. This wide range is likely because of the inconsistencies in the definition and reporting patterns for PIN in the older reports. More recently, the incidence of HGPIN alone in the biopsy specimen is between $1 \%$ and $4 \% .{ }^{34,35}$

Because of the close association between HGPIN and cancer, the general recommendation and standard practice has been to perform a second biopsy in men diagnosed with HGPIN alone. This recommendation was further supported by a number of studies that reported a cancer detection rate of $40 \%$ to $70 \%$, as outlined in Table 5. These studies included men whose first biopsy was performed using the sextant scheme..$^{36-38,40}$ As mentioned previously (Table 2), with the sextant scheme, nearly $30 \%$ of cancers were found in repeat biopsy alone, even in the absence of these high-risk pathologic features.

Over the past few years, the extended biopsy schemes have become popular because of the associated increase in the cancer detection rate at first biopsy. With improvements in prostate sampling at first biopsy, one would expect a decrease in the number of cancers found in the repeat biopsy. Recent studies on repeat biopsy performed for HGPIN after initial extended biopsies have reported this decrease in the cancer detection rate (Table 5). Although not strictly using an extended scheme, Lefkowitz et al..$^{41}$ found cancer in only 1 of $43(2.3 \%)$ men with HGPIN who had previously undergone a 12 -core ( 2 sextants) biopsy of the prostate. The report from M. D. Anderson

\begin{tabular}{|c|c|c|c|c|}
\hline $\begin{array}{l}\text { Author } \\
\text { Year }\end{array}$ & $\begin{array}{l}\text { Initial biopsy } \\
\text { scheme }^{\text {a }}\end{array}$ & $\begin{array}{l}\text { With HGPIN } \\
N\end{array}$ & $\begin{array}{l}\text { With cancer } \\
N\end{array}$ & $\begin{array}{l}\text { With cancer } \\
\%\end{array}$ \\
\hline $\begin{array}{l}\text { Weinstein et al. }{ }^{36} \\
1993\end{array}$ & Sextant & 33 & 10 & 31 \\
\hline $\begin{array}{l}\text { Davidson et al. }{ }^{37} \\
1995\end{array}$ & Sextant & 100 & 35 & 35 \\
\hline $\begin{array}{l}\text { Aboseif et al. }{ }^{38} \\
1995\end{array}$ & Sextant & 24 & 19 & 79 \\
\hline $\begin{array}{l}\text { Raviv et al. } \\
1996\end{array}$ & Sextant & 48 & 23 & 48 \\
\hline $\begin{array}{l}\text { O'Dowd et al. }{ }^{39} \\
2000\end{array}$ & Mostly sextant & 1306 & 295 & 26 \\
\hline $\begin{array}{l}\text { Kronz et al. }{ }^{40} \\
2001\end{array}$ & Sextant & 245 & 79 & 32 \\
\hline $\begin{array}{l}\text { Lefkowitz et al. }{ }^{41} \\
2001\end{array}$ & $\begin{array}{l}2 \text { sextants } \\
\text { (12 cores) }\end{array}$ & 43 & 1 & 2.3 \\
\hline $\begin{array}{l}\text { Mian et al. } .^{25} \\
2002\end{array}$ & $\begin{array}{l}\text { Extended } \\
\text { (11-core) }\end{array}$ & 27 & 1 & 3.7 \\
\hline $\begin{array}{l}\text { Moore et al. }{ }^{26} \\
2003\end{array}$ & $\begin{array}{l}\text { Extended } \\
(>10 \text { core })\end{array}$ & 34 & 2 & 5.8 \\
\hline
\end{tabular}

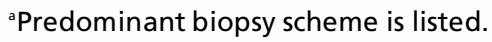


Cancer Center ${ }^{25}$ noted cancer in only 1 of 27 men with HGPIN after an extended, multisite biopsy. Analysis of our repeat biopsy population found a similarly low cancer detection rate in 34 men with HGPIN that was detected with an extended biopsy scheme. ${ }^{26}$ This included 14 men who underwent 2 repeat extended biopsies.

When compared with results in the sextant biopsy era, currently men with HGPIN detected through an initial extended biopsy do not seem to be at high risk of having cancer found in the repeat biopsy. In contradistinction to previous reports, the evidence from contemporary reports on HGPIN does not warrant a repeat biopsy in men with HGPIN. In my current practice, I do not perform a repeat biopsy in men with HGPIN if I have thoroughly sampled the peripheral zone using the above-mentioned extended biopsy scheme.

In the past, an interval of a few weeks to few months was thought to be optimal for re-biopsy in men with HGPIN. Although the presence of HGPIN, in my mind, is no longer an indication for immediate repeat biopsy, one report suggests that men with HGPIN may be at high risk of developing clinically detectable cancer in the future. ${ }^{42}$ The authors performed a 12-core ( 2 sextants) biopsy in 31 men 3 years after the initial 12 -core biopsy revealed HGPIN. Cancer was detected in 8 of $31(25 \%)$ men with an average Gleason score of 6 . Although the PSA level increased by an average of $2.8 \mathrm{ng} / \mathrm{mL}$, it was not predictive of cancer on univariate analysis. Although interesting, the findings of this small study need fur- ther validation on larger cohort of patients. At this time, not enough evidence exists to recommend a repeat biopsy in these men several years later, and we continue to monitor PSA level as the trigger for a repeat biopsy.

\section{Atypical Small Acinar Proliferation}

Atypical small acinar proliferation (ASAP) refers to foci of atypical glands not considered diagnostic of carcinoma because of either the presence of too few glands with features of carcinoma or the absence of definitive architectural or cytologic features of malignancy. ${ }^{43}$ The diagnosis of ASAP requires evaluation of deeper tissue sections and special stains with high molecular weight cytokeratin $(34 \beta \mathrm{E} 12) .^{25}$

The presence of ASAP in the biopsy specimen has been associated with a high risk of finding cancer on subsequent biopsies. The cancer was detected in 30\% to $60 \%$ of men undergoing repeat biopsy following a sextant biopsy that showed ASAP. Unlike HGPIN, ASAP detected after an extended biopsy continues to be associated with a high risk of cancer ${ }^{39,43-45}$ that is similar to the risk after a sextant biopsy (Table 6).

Although based on a small number of men, a study from M. D. Anderson Cancer Center reported a cancer detection rate of $70 \% .{ }^{25}$ We found cancer in 18 of 50 men (36\%) after the initial extended biopsy showed the presence of ASAP. ${ }^{26}$ Interestingly, cancer was found in only 3 of the $22(14 \%)$ men who underwent a third biopsy for ASAP, a rate similar to those who underwent a third biopsy for clinical indications.

The finding that ASAP continues to be associated with a high risk of cancer in repeat biopsy is not

\begin{tabular}{|c|c|c|c|c|}
\hline $\begin{array}{l}\text { Author } \\
\text { year }\end{array}$ & $\begin{array}{l}\text { Initial biopsy } \\
\text { scheme }^{\text {a }}\end{array}$ & $\begin{array}{l}\text { With ASAP } \\
N\end{array}$ & $\begin{array}{l}\text { With cancer } \\
N\end{array}$ & $\begin{array}{l}\text { With cancer } \\
\%\end{array}$ \\
\hline $\begin{array}{l}\text { Iczkowski et al. }{ }^{43} \\
1997\end{array}$ & Sextant & 33 & 15 & 45 \\
\hline $\begin{array}{l}\text { Renshaw et al. }{ }^{45} \\
1998\end{array}$ & Sextant & 59 & 20 & 34 \\
\hline $\begin{array}{l}\text { Chan et al. }{ }^{22} \\
1999\end{array}$ & Sextant & 92 & 45 & 49 \\
\hline $\begin{array}{l}\text { O'Dowd et al. }{ }^{39} \\
2000\end{array}$ & Sextant & 1321 & 529 & 40 \\
\hline $\begin{array}{l}\text { Park et al. } .^{44} \\
2001\end{array}$ & Sextant & 45 & 23 & 51 \\
\hline $\begin{array}{l}\text { Mian et al. }{ }^{25} \\
2002\end{array}$ & $\begin{array}{l}\text { Extended } \\
\text { (11-core) }\end{array}$ & 10 & 7 & 70 \\
\hline $\begin{array}{l}\text { Moore et al. }{ }^{26} \\
2003\end{array}$ & $\begin{array}{l}\text { Extended } \\
(>10 \text { core) }\end{array}$ & 50 & 18 & 36 \\
\hline
\end{tabular}

aPredominant biopsy scheme is listed. 
surprising. In our view and that of others, ${ }^{46}$ a diagnosis of ASAP merely represents an undersampling of an existing malignant lesion or detection of a minute cancer focus. Thus, all men with the diagnosis of ASAP in the biopsy specimen should undergo an immediate repeat biopsy.

Clearly, the prognostic value of ASAP and HGPIN in predicting cancer in repeat biopsy varies significantly. Many of the studies from the sextant biopsy era had combined both of these entities under one heading and reported a combined cancer detection rate. In the extended biopsy era, future studies must analyze the significance of these two pathologic lesions separately because a dramatic difference exists in the cancer detection rates for HGPIN and ASAP.

\section{Repeat Biopsy Scheme}

As is evident from previously mentioned reports, the sextant biopsy missed a significant number of cancers, most of which were found in the extended (lateral horn of peripheral zone) biopsy sites. In the extended biopsy era, when a repeat biopsy is performed for clinical indications, a significant number of cancers are found only in the additional sites (Table 4). Thus, for repeat biopsy in men with PSA-related abnormalities or abnormal DRE, the scheme should include extended peripheral zone biopsy plus at least one transition zone biopsy from each lobe. In recent years, because of the extended prostate sampling, the cancer detection rate for HGPIN has declined dramatically. Thus, it is not possible to make meaningful statements regarding the repeat biopsy scheme, because a repeat biopsy is not necessary in these men.

Because ASAP is thought to represent undersampling of a cancer lesion, the fact that most of the cancers in repeat biopsy are found at or near the site of ASAP is not surprising. ${ }^{44,47}$ However, this approach missed $12 \%$ to $15 \%$ of the cancers. Using the extended biopsy scheme, we found that - with rare exceptionsalmost all of the cancers were found ipsilateral to the side of ASAP; however, targeting the specific biopsy site where ASAP was found could miss up to $50 \%$ of cancers. $^{25,26}$

The added morbidity of bilateral biopsies over unilateral biopsies is negligible, and the presence of ASAP probably signifies the only truly high-risk group. Therefore, we prefer to use the same extended biopsy scheme as for the initial biopsy, to minimize the false negative rate.

\section{Saturation Biopsies}

Recently, a few investigators have recommended use of "saturation" biopsy technique in men undergoing repeat biopsy. ${ }^{48,49}$ The procedure involves taking as many as an average of 23 biopsy cores, and the cancer detection rates have ranged from $30 \%$ to $35 \%$. It is, however, difficult to draw meaningful conclusions from these results because the indications for repeat biopsies included men with abnormal PSA and DRE as well as HGPIN and atypia. Furthermore, this approach requires the use of general anesthesia or intravenous sedation, and possibly an outpatient surgical facility. A high rate of complications ( $10 \%$ to $15 \%)$ is associated with this procedure, including gross hematuria, urinary retention, hospitalization, rectal bleeding, and sepsis.

Because of the associated cost and high morbidity rate, we cannot recommend this approach at this time, especially when the cancer detection rates are not significantly superior to the other repeat biopsy techniques.

\section{Summary}

The extended biopsy schemes have revolutionized our ability to detect an increasing number of cancers without compromising patient safety. At present, the optimal biopsy scheme is an extended biopsy with 10 to 12 peripheral zone cores and reserving the transition zone biopsies for repeat biopsies only. The presence of HGPIN in biopsy specimens is no longer an ominous finding and this situation does not require a repeat biopsy. However, men with ASAP must undergo a repeat extended biopsy of the prostate as soon as possible.

\section{References}

1. Jemal A, Murray T, Samuels A, et al. Cancer statistics, 2003. CA Cancer J Clin 2003;53:5-26.

2. Hodge KK, McNeal JE, Terris MK, et al.: Random systematic versus directed ultrasound guided transrectal core biopsies of the prostate. J Urol 1989;142:71-74.

3. Stamey TA. Making the most out of six systematic sextant biopsies. Urology 1995;45:2-12.

4. Catalona WJ, Richie JP, Ahmann FR, et al. Comparison of digital rectal examination and serum prostate specific antigen in the early detection of prostate cancer: results of a multicenter clinical trial of 6,630 men. J Urol 1994;151: 1283-1290.

5. Chang JJ, Shinohara K, Bhargava V, et al. Prospective evaluation of lateral biopsies of the peripheral zone for prostate cancer detection. J Urol 1998;160:2111-2114. 
6. Reissigl A, Pointner J, Strasser H, et al. Frequency and clinical significance of transition zone cancer in prostate cancer screening. Prostate 1997;30:130-135.

7. Bazinet M, Karakiewicz PI, Aprikian AG, et al. Value of systematic transition zone biopsies in the early detection of prostate cancer. J Urol 1996;155:605-606.

8. Onder AU, Yalcin V, Arar O, et al. Impact of transition zone biopsies in detection and evaluation of prostate cancer. Eur Urol 1998;33:542-548.

9. Fowler JE Jr, Bigler SA, Kilambi NK, et al. Results of transition zone biopsy in black and white men with suspected prostate cancer. Urology 1999;53:346-350.

10. Maeda $\mathrm{H}$, Ishitoya S, Aoki $Y$, et al.: Value of systematic transition zone biopsy in the detection of prostate cancer. Int J Urol 1997;4:567-571.

11. Lui PD, Terris MK, McNeal JE, et al. Indications for ultrasound guided transition zone biopsies in the detection of prostate cancer. J Urol 1995;153:1000-1003.

12. Liu IJ, Macy M, Lai Y, et al. Critical evaluation of the current indications for transition zone biopsies. Urology 2001;57:1117-1120.

13. Keetch DW, Catalona WJ, Smith DS. Serial prostatic biopsies in men with persistently elevated serum prostate specific antigen values. J Urol 1994;151:1571-1574.

14. Roehrborn CG, Pickens GJ, Sanders JS. Diagnostic yield of repeated transrectal ultrasound-guided biopsies stratified by specific histopathologic diagnoses and prostate specific antigen levels. Urology 1996;47:347-352.

15. Fleshner NE, O'Sullivan M, Fair WR. Prevalence and predictors of a positive repeat transrectal ultrasound guided needle biopsy of the prostate. J Urol 1997;158:505-508.

16. Levine MA, Ittman M, Melamed J, et al. Two consecutive sets of transrectal ultrasound guided sextant biopsies of the prostate for the detection of prostate cancer. J Urol 1998;159:471-475.

17. Eskew LA, Bare RL, McCullough DL. Systematic 5 region prostate biopsy is superior to sextant method for diagnosing carcinoma of the prostate. J Urol 1997;157:199-202.

18. Babaian RJ, Toi A, Kamoi K, et al. A comparative analysis of sextant and an extended 11-core multisite directed biopsy strategy. J Urol 2000;163:152-157.

19. Chen ME, Troncoso P, Johnston DA, et al. Optimization of prostate biopsy strategy using computer based analysis. J Urol 1997;158:2168-2175.

20. Presti JC Jr, Chang JJ, Bhargava V, et al. The optimal systematic prostate biopsy scheme should include 8 rather than 6 biopsies: results of a prospective clinical trial. J Urol 2000;163:163-166.

21. Gore JL, Shariat SF, Miles BJ, et al. Optimal combinations of systematic sextant and laterally directed biopsies for the detection of prostate cancer. J Urol 2001;165:1554-1559.

22. Chan TY, Chan DY, Stutzman KL, et al. Does increased needle biopsy sampling of the prostate detect a higher number of potentially insignificant tumors? J Urol 2001;166: 2181-2184.
23. Taylor JA 3rd, Gancarczyk KJ, Fant GV, et al. Increasing the number of core samples taken at prostate needle biopsy enhances the detection of clinically significant prostate cancer. Urology 2002;60:841-845.

24. Fink KG, Hutarew G, Pytel A, et al. One 10-core prostate biopsy is superior to two sets of sextant prostatebiopsies. BJU Int 2003;92:385-388.

25. Mian BM, Naya Y, Okihara K, et al. Predictors of cancer in repeat extended multisite prostate biopsy in men with previous negative extended multisite biopsy. Urology 2002;60:836-840.

26. Moore M, Lehr D, Nazeer T, et al. Significance of high grade prostatic intraepithelial neoplasia and atypical small acinar proliferation in the contemporary era. (submitted for publication)

27. Haussler O, Epstein JI, Amin MB, et al. Cell proliferation, apoptosis, oncogene, and tumor suppressor gene status in adenosis with comparison to benign prostatic hyperplasia, prostatic intraepithelial neoplasia, and cancer. Hum Pathol 1999;30:1077-1086.

28. Bostwick DG. Prostatic intraepithelial neoplasia is a risk factor for cancer. Semin Urol Oncol 1999;17:187-198.

29. Greenberg NM, DeMayo F, Finegold MJ, et al. Prostate cancer in a transgenic mouse. Proc Natl Acad Sci USA 1995;92:3439-3443.

30. Xie W, Wong YC, Tsao SW. Correlation of increased apoptosis and proliferation with development of prostatic intraepithelialneoplasia (PIN) in ventral prostate of the Noble rat. Prostate 2000;44:31-39.

31. Prange W, Erbersdobler A, Hammerer $P$, et al. High-grade prostatic intraepithelial neoplasia in cystoprostatectomyspecimens. Eur Urol 2001;39(suppl4):30-31.

32. Oyasu R, Bahnson RR, Nowels K, et al. Cytological atypia in the prostate gland: frequency, distribution and possible relevance to carcinoma. J Urol 1986;135:959-962.

33. McNeal JE, Bostwick DG. Intraductal dysplasia: a premalignant lesion of the prostate. Hum Pathol 1986;17:64-71.

34. HoedemaekerRF, Kranse R, Rietbergen JB, et al. Evaluation of prostate needle biopsies in a population-based screening study: the impact of borderline lesions. Cancer 1999;85: $145-152$.

35. Orozco R, O’Dowd G, Kunnel B, et al. Observations on pathology trends in 62,537 prostate biopsies obtained from urology private practices in the United States. Urology 1998;51:186-195; erratum: 1998;51:523.

36. Weinstein MH, Epstein JI. Significance of high-grade prostatic intraepithelial neoplasia on needle biopsy. Hum Pathol 1993;24:624-629.

37. Davidson D, Bostwick DG, Qian J, et al. Prostatic intraepithelial neoplasia is a risk factor for adenocarcinoma: predictive accuracy in needle biopsies. J Urol 1995;154:1295-1299.

38. AboseifS, Shinohara K, Weidner N, et al. The significance of prostatic intra-epithelial neoplasia. Br J Urol 1995; 76:355-359.

39. O'Dowd GJ, Miller MC, Orozco R, et al. Analysis of repeated biopsy results within 1 year after a noncancer diagnosis. Urology 2000;55:553-559. 
Mian

40. Kronz JD, Allan CH, Shaikh AA, et al. Predicting cancer following a diagnosis of high-grade prostatic intraepithelial neoplasia on needle biopsy: data on men with more than one follow-up biopsy. Am J Surg Pathol 2001;25:1079-1085.

41. Lefkowitz GK, Sidhu GS, Torre P, et al. Is repeat prostate biopsy for high-grade prostatic intraepithelial neoplasia necessary after routine 12-core sampling? Urology 2001;58: 999-1003.

42. Lefkowitz GK, Taneja SS, Brown J, et al. Followup interval prostate biopsy 3 years after diagnosis of high grade prostatic intraepithelial neoplasia is associated with high likelihood of prostate cancer, independent of change in prostate specific antigen levels. J Urol 2002;168:1415-1418.

43. IczkowskiKA, MacLennan GT, Bostwick DG. Atypicalsmall acinar proliferation suspicious for malignancy in prostate needle biopsies: clinical significance in 33 cases. Am J Surg Pathol 1997;21:1489-1495.

44. Park S, Shinohara K, Grossfeld GD, et al. Prostate cancer detection in men with prior high grade prostatic intraepithe- lial neoplasia or atypical prostate biopsy. J Urol 2001;165: 1409-1414.

45. Renshaw AA, Santis WF, Richie JP. Clinicopathological characteristics of prostatic adenocarcinoma in men with atypical prostate needle biopsies. J Urol 1998;159:2018-2021.

46. Iczkowski KA, Chen HM, Yang XJ, et al. Prostate cancer diagnosed after initial biopsy with atypical small acinar proliferation suspicious for malignancy is similar to cancer found on initial biopsy. Urology 2002;60:851-854.

47. Allen EA, Kahane H, Epstein JI. Repeat biopsy strategies for men with atypical diagnoses on initial prostate needle biopsy. Urology 1998;52:803-807.

48. Stewart CS, Leibovich BC, Weaver AL, et al. Prostate cancer diagnosis using a saturation needle biopsy technique after previous negative sextant biopsies. J Urol 2001;166:86-91.

49. Borboroglu PG, Comer SW, Riffenburgh RH, et al. Extensive repeat transrectal ultrasound guided prostate biopsy in patients with previous benign sextant biopsies. J Urol 2000;163: 158-162. 